\title{
Analysis of genetic diversity among the maize inbred lines (Zea mays L.) under heat stress condition
}

\author{
${ }^{1}$ Manoj Kandel, ${ }^{1}$ Surya Kant Ghimire, ${ }^{1}$ Bishnu Raj Ojha and ${ }^{2}$ Jiban \\ Shrestha \\ ${ }^{1}$ Department of Genetics and Plant breeding, Agriculture and Forestry University \\ (AFU), Rampur, Chitwan, Nepal \\ ${ }^{2}$ Nepal Agricultural Research Council, National Maize Research Program \\ (NMRP), Rampur, Chitwan, Nepal \\ Corresponding Author Email: manojkandel24@gmail.com \\ *ORCID: https://orcid.org/0000-0002-3929-0426
}

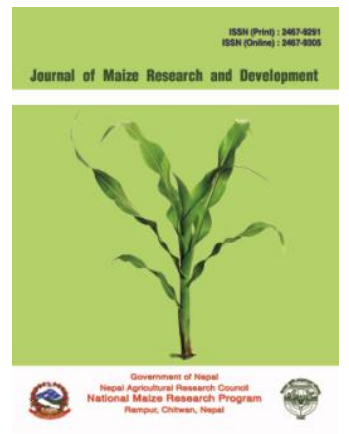

Received: August 05, 2017; Revised: October 18, 2017; Accepted: December 20, 2017

(C) Copyright 2017 Kandel et al.

under a Creative Commons Attribution-NonCommercial 4.0 International License.

\begin{abstract}
High temperature adversely affects the plant physiological processes: limits plant growth and reduction in grain yield. Heat stress is often encountered to spring sowing of maize in spring season. Twenty maize inbred lines were studied for days to $50 \%$ anthesis and silking, anthesis-silking interval, leaf firing, tassel blast, SPAD reading and leaf senescence, plant and ear height, leaf area index, ear per plant, cob length and diameter, number of kernel/ear, number of kernel row/ear, number of kernel row, silk receptivity, shelling percentage, thousand kernel weight and grain yield in alpha lattice design at National Maize Research Program at Rampur, Chitwan,Nepal with the objective to identify superior heat stress tolerant lines. Analysis of variance showed significant difference for all the traits. Result of multivariable analysis revealed that twenty inbred lines formed four clusters. The resistance inbred lines and susceptible inbred lines formed different clusters. The members of cluster 4 were found to be tolerant to heat stress due to they had lowest value of tassel blast, leaf firing, and leaf area index with highest value of cob diameter and length, ear per plant, number of kernel row/ear, number of kernel/ear, number of kernel row, shelling percentage, silk receptivity and grain yield whereas as members of cluster 1were found most susceptible due to they had longer anthesis silking interval, with maximum tassel blast and leaf firing along with no grain yield under heat stress condition. From this study inbred lines RL-140, RML-76, RML-91 and RML-40 were found most tolerant to heat stress. These inbred lines belonging to superior cluster could be considered very useful in developing heat tolerant variety and other breeding activities.
\end{abstract}

Keywords: Maize (Zea mays L.), Genetic divergence, Heat stress, Multivariable analysis

Correct citation: Kandel, M., Ghimire, S. K., Ojha, B. R., \& Shrestha, J. (2017). Analysis of genetic diversity among the maize inbred lines (Zea mays L.) under heat stress condition. Journal of Maize Research and Development, 3 (1), 86-97. doi: http://dx.doi.org/10.3126/jmrd.v3i1.18925 


\section{INTRODUCTION}

Maize (Zea Mays L.) is an important cereals crop belongs to the tribe Maydeae, of the grass family, Poaceae and popularly known as the 'queen of cereals' (Dhaka et al., 2010).It is important cereal crop worldwide after wheat and rice in worldwide and second most staple food crop both in term of area and production after rice in Nepal. It is grown in 8, 91,583 ha producing 2.2 million tons, with an average yield of $2500 \mathrm{~kg} / \mathrm{ha}$ (MoAD, 2016). Beside direct consumption as food, it is also an important source of industrials raw materials example the manufacture a starch, dextrose, oil sugar, syrup, enzymes, adhesive paper and plastic. Maize demand will be double in developing world in 2050 and it predicted as crop of greatest production globally and in developing world by 2025 (Rosegrant et al., 2008).

Climate change effects such as global warming is major challenge on crop production and identify possible ways that would allow yield ceilings to shift by developing improved thermos tolerant cultivars. Therefore these efforts are particularly important in south Asia, where current production systems are not sustainable and could be adversely impacted by climate change in the near future (Niyogi et al., 2010). Heat and drought stress have emerged as a common problem worldwide which can reduce maize crop productivity (Ali et al., 2015 ).A record drop in maize production was reported in many maize-growing areas of the world (Van der Velde et al., 2010).It is predicted that maize yield might be reduced up $70 \%$ due to increasing temperatures (Khodarahmpour et al., 2011).

Genetic diversity analysis is imperative in crop improvement and can be studied through morphological, biochemical and molecular markers. Morphological characterization for genetic divergence among genotypes is considered an initial step (Khan et al., 2014). Therefore morphological data has play key role in management of genetic resources. To management of genetic resource study relationships and description and classification of germplasm the morphological characterization is the first step (Smith \& Smith, 1989).Cluster analysis is frequently used to classify maize accessions and can be used by breeders and geneticists to identify subsets of accessions which have potential utility for specific breeding or genetic purposes (Rincon et al., 1996).

The main aim of using a cluster technique in plant breeding trials is to group the varieties into several homogeneous groups such that those varieties within a group have a similar response pattern across the locations. Many researchers have used principal component analysis to assess genetic variability among maize genotypes because it retrieves small numbers of components that account for most of the variations in the data (Asare, 2016). The objective of the research was to identify superior heat stress tolerant inbred lines after clustering them based on their response to heat stress condition.

\section{METERIALS AND METHOD}

The research was conducted at National Maize Research Program (NMRP) of Rampur, Chitwan Nepal during spring season from February 24, 2015 to July 2016, geographically located at $27^{\circ}$ $37^{\prime}$ North Latitude and $84^{\circ} 29^{\prime}$ East longitude at an altitude of 225 meter above sea level. This site contains only sandy loam soil with acidic reaction. This research location is characteristics of subtropical climate. The plant materials were collected from National Maize Research Program 
Journal of Maize Research and Development (2017) 3 (1): 86-97

ISSN: 2467-9291 (Print), 2467-9305 (Online)

DOI: http://dx.doi.org/10.3126/jmrd.v3i1.18925

(NMRP).The list of inbred lines along with pedigree information included in the study is presented in Table 1.

Table 1: Names and pedigree information of maize inbred lines used for heat stress research at NMRP Chitwan (2016).

\begin{tabular}{llllll}
\hline S.N & $\begin{array}{l}\text { Inbred line of } \\
\text { maize }\end{array}$ & Pedigree sources/origin & S.N & $\begin{array}{l}\text { Inbred line of } \\
\text { maize }\end{array}$ & Pedigree sources/origin \\
\hline 1 & NML-2 & CML-430 & 11 & RL-101 & UPAHAR-B-20-2-3-1-1 \\
2 & RML-4 & CA00326 & 12 & RML-24 & CA00304 \\
3 & RML-32 & CA00320 & 13 & RML-40 & CML-427 \\
4 & RML-95 & PUTU-17 & 14 & RML-57 & CLQG6602 \\
5 & RML-86 & PUTU-20 & 15 & RL-107 & UPAHAR-B-20-2-4-3-1 \\
6 & RML-17 & CML-287 & 16 & RML-20 & CA-34503 \\
7 & RML-96 & AG-27 & 17 & RML-76 & CLRCYQ007 \\
8 & RL-105 & UPAHAR-B-20-2-4-1-1 & 18 & RML-7 & CML-413 \\
9 & RL-111 & UPAHAR-B-31-1-1-1-1 & 19 & RML-91 & PUTU-19 \\
10 & RML-115 & PUTU-17 & 20 & RL-140 & POOL-21-12-1-2-2-1-1 \\
\hline
\end{tabular}

Field experiment was conducted in alpha lattice design. There were two conditions: normal and plastic house (for heat stress), each condition replicated twice. Each replication comprised four blocks consisting of five plots each. Each plot was 3 meter in length 0.6 meter wide. Each plot had one row with spacing $20 \mathrm{~cm}$ between rows, inter block gap was $0.5 \mathrm{~m}$ was maintained. Each plot contained single row with spacing $60 \times 20 \mathrm{~cm}$ and consisted 15 hills, each of two seed were sown, one of whose seedling were removed at the six leaves stage. The dose of chemical fertilizer applied was 120:60:40 kg NPK per hectare. Fertilizer were applied prior to sowing at rate of $\mathrm{N} 60 \mathrm{~kg} / \mathrm{ha}, \mathrm{P} 60 \mathrm{~kg} / \mathrm{ha}$ and K $40 \mathrm{~kg} / \mathrm{ha}$ and additional side dressing of $30 \mathrm{~N} \mathrm{~kg} / \mathrm{ha}$ were applied at the two times in six leaves stage and knee high stage of maize. The irrigation was done three important stage, knee high stage, tasseling stage and milking stage. To created heat stress condition maize study half of field was controlled heating imposed using two plastic (120gsm) houses were used two week just prior to the onset of reproductive period up to the crop harvesting. Maximum mean temperature $46.2^{\circ} \mathrm{C}$ in April in heat stress condition whereas as normal condition was $37.23^{\circ} \mathrm{C}$ and similarly for May month in maximum mean temperature was $43.28^{\circ} \mathrm{C}$ whereas in normal condition $34.54^{\circ} \mathrm{C}$ means mean temperature $8-9^{\circ} \mathrm{C}$ higher in plastic house at time of flowering, pollination and grain filling periods responsible for creates heat stress condition as shown in Fig 1.Partial opening top side of tunnel was done for control relative humidity inside tunnel to avoid any possible disease outbreak. 
Journal of Maize Research and Development (2017) 3 (1): 86-97

ISSN: 2467-9291 (Print), 2467-9305 (Online)

DOI: http://dx.doi.org/10.3126/jmrd.v3i1.18925

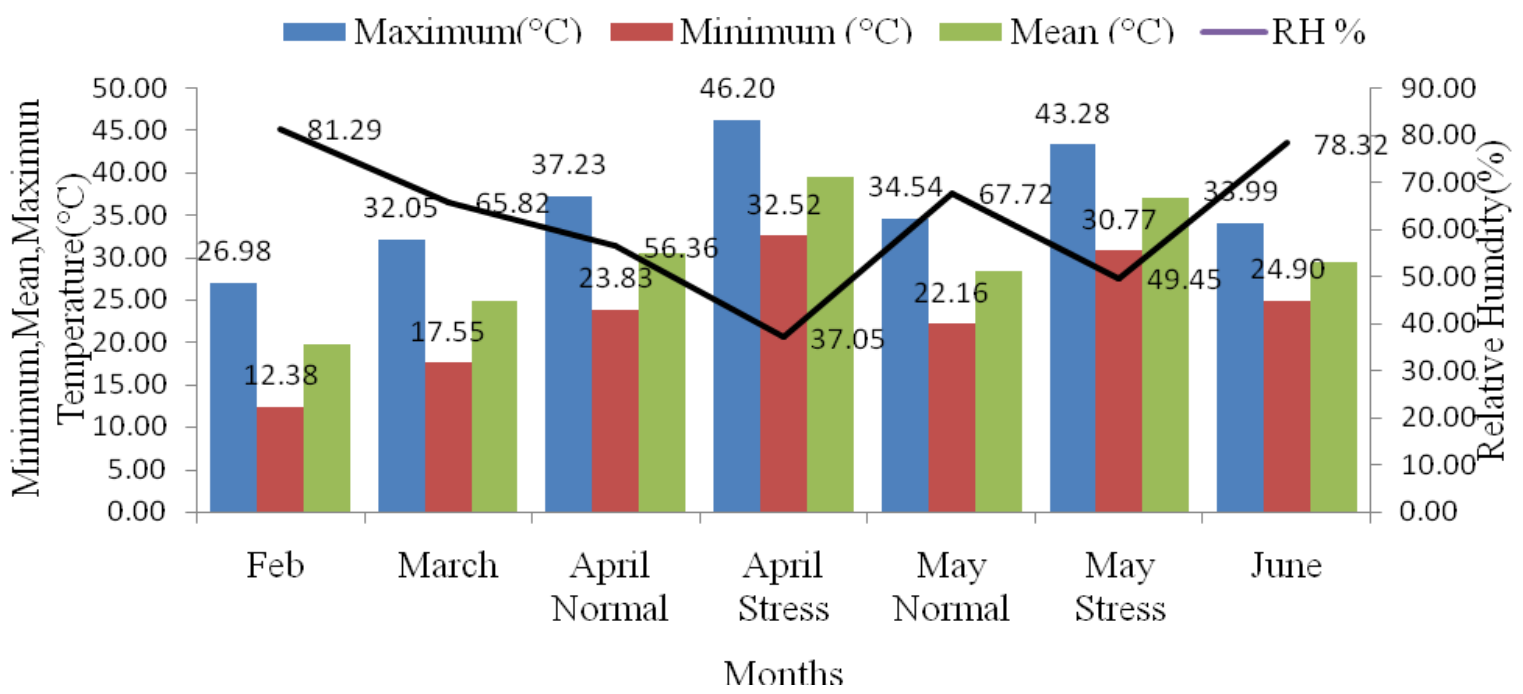

Figure 1: Weather and stress data during the growing period of maize at NMRP, Chitwan (2016).

\section{Data collection}

Data on days to 50\% anthesis, days to 50\% silking and ears per plot, leaf firing, tassel blast, leaf senescence were recorded on plot basis. Whereas, ear height $(\mathrm{cm})$, number of kernels/cob, number of kernel row, number of kernel row/ear, SPAD reading, leaf area index, silk receptivity, thousand kernel weight $(\mathrm{g})$ and shelling per cent were recorded on five selected representative plants. The sample cobs were shelled, cleaned and grain weight and shank weight were recorded to calculate the shelling percent. Thousand kernel weight was measured by counting 1000 grains from the bulk of each plot after shelling and weighed in grams after the moisture was adjusted to $15 \%$. Anthesis-silking interval (ASI) was calculated by subtracting the number of days taken for $50 \%$ anthesis from the number of days taken to50\% silk emergence. Leaf area index was calculated by total leaf area divided by land area and multiply by correction factor (0.75). Silk receptivity was recorded by total number of fertilized grains per ear divided by number of potential grain per ear. Leaf firing was obtained by the counting the number of plants that showed leaf firing symptoms (younger leaves near tassel burnt or dried) in the total number of plants in a particular plot and was expressed in percentage. Tassel blast was obtained by the counting the number of plants that showed tassel blast symptoms (tassel dried with partial or no pollen shedding) in the total number of plants in particular plot was expressed in percentage. Grain yield was calculated using formula adopted by Carangal et al. (1971) and Shrestha et al. (2015) by adjusting the grain moisture at $15 \%$ and converted to the grain yield per hectare.

\section{Statistical Analysis}

The data recorded on different parameters from in heat stress field were first tabulated and processing in Microsoft excel (MS- Excel, 2010), then subjected to restricted maximum likelihood (REML) tool in GenStat to obtain ANOVA. These collected data were subjected to cluster analysis (average linkage method) and principal component analysis using statistical software packages of Minitab ver.17. 
Journal of Maize Research and Development (2017) 3 (1): 86-97

ISSN: 2467-9291 (Print), 2467-9305 (Online)

DOI: http://dx.doi.org/10.3126/jmrd.v3i1.18925

\section{RESULTS}

The present study genetic diversity for heat stress tolerance was analyzed among 20 maize inbred lines on the basis of 19 agro morphological traits. The result of descriptive analysis (Table1) showed that leaf firing percentage had highest variation (52.3) fallowed by tassel blast percentage (22.93), anthesis silking interval (21.9), SPAD (14.22).Among trait plant physiological maturity showed the lowest variation (1.5). Significant variation among inbred lines differences for grain yield and anthesis silking interval, SPAD reading and leaf senescence, tassel blast and leaf firing percentage, plant and ear height, leaf area index, ear per plant, cob length and diameter, number of kernel/ear, number of kernel row, number kernel/ear, silk receptivity, shelling percentage, thousand kernel weight under heat stress condition. The mean value of observed traits anthesis silking interval, leaf area index, leaf firing, tassel blast, leaf senescence, SPAD, plant height, ear height, plant maturity, cob length, cob diameter, number of kernel row/ear, number kernel/ear, number of kernel row, silk receptivity, shelling percentage, thousand kernel weight and grain yield as presented in Table 1.Inbred lines RML-91 (716.8 $\mathrm{kg} / \mathrm{ha}$ ) fallowed by RL-140 (702.9 kg/ha) and RML-76 (689.5 kg/ha) produces maximum yield whereas as inbred lines NML-2, RL-105, RL-111, RML-115, RML-24, RML-4, RML-86, and RML-95 produces barren cob under heat stress condition.

Table 1: Descriptive statistics of agro morphological traits of 20 maize inbred lines at NMRP, Rampur, Chitwan (2016 spring)

\begin{tabular}{llllllllll}
\hline Statistics & Mean & F-test & CV\% & LSD & Statistics & Mean & F-test & CV\% & LSD \\
\hline ASI & 3.8 & $*$ & 21.9 & 1.8 & CD & 1.677 & $* *$ & 14.66 & 0.532 \\
LAI & 2.64 & $*$ & 12 & 0.7 & CL & 6.89 & $* *$ & 12.97 & 1.931 \\
LF & 18 & $*$ & 52.3 & 20.8 & NKRE & 6.64 & $* *$ & 7.2 & 1.037 \\
TB & 35.6 & $* *$ & 22.93 & 17.64 & NKE & 42.1 & $* *$ & 21 & 19.21 \\
LS & 63.8 & $* *$ & 12.4 & 17.2 & NKR & 7.82 & $* *$ & 13.52 & 2.284 \\
SPAD & 38.16 & $*$ & 14.22 & 11.723 & SR\% & 17.23 & $* *$ & 11.57 & 4.31 \\
PH & 129.9 & $*$ & 7.91 & 22.21 & SP\% & 26.79 & $* *$ & 14.7 & 8.56 \\
EH & 66.6 & $* *$ & 8.13 & 11.7 & TKW & 164.8 & $* *$ & 6 & 21.61 \\
PM & 106.5 & $* *$ & 1.5 & 3.432 & GY & 316 & $* *$ & 8.62 & 58.89 \\
EPP & 1.168 & $*$ & 15 & 0.379 & & & & &
\end{tabular}

\section{Cluster Analysis}

All the inbred lines were clustered using day to $50 \%$ tasseling and silking, anthesis-silking interval (ASI), leaf firing, tassel blast, SPAD reading and leaf senescence, plant and ear height, leaf area index, ear per plant, cob length and diameter, number of kernel/ear, number of kernel row, number kernel/ear, silk receptivity, shelling percentage, thousand kernel weight at heat stress condition as variables. The dendrogram reveled four clusters with minimum of $22.47 \%$ similarity level in UPGMA Clustering. The distance between the clusters centroid was found highest between clusters 1 and 4 and lowest between clusters 2 and 4 is presented in Table 2. The clusters were divided into two groups: group A and Group B. Group A consisted of one cluster named as cluster one whereas group B consisted of three clusters namely Cluster2, Cluster 3 and cluster 4. Cluster 1 consisted of 8 lines named as NML-2, RL-105, RML-24, RL-111, RML-4, 
Journal of Maize Research and Development (2017) 3 (1): 86-97

ISSN: 2467-9291 (Print), 2467-9305 (Online)

DOI: http://dx.doi.org/10.3126/jmrd.v3i1.18925

RML-86, RML-95 and RML-115 which represent $40 \%$ of total lines. Inbred lines grouped in this cluster had longer anthesis silking interval, with maximum tassel blast and leaf firing along with zero value for grain yield including cob length, cob diameter and length, number of kernel row/ear, number of kernel/ear, number of kernel row, shelling percentage, silk receptivity and thousand kernel weight. The lines of this cluster are most susceptible to heat stress. Cluster 2 consisted of 5 lines named as RL-101, RML-17, RML-32, RML-96 and RML-7, 25\% of total lines was characterized with had highest leaf senescence fallowed by thousand kernel weight and lowest for cob diameter and length, ear per plant, number of kernel row/ear, number of kernel/ear and number of kernel row. The inbred lines categorized into cluster 3 were RL-107, RML-20 \&RML-57, $15 \%$ of total lines had shorter plant and ear height, late physiological maturity and highest for ear per plant. Cluster 4 consisted of 4 lines named as RL-140, RML-76, RML-91 and RML-40, 20 \% of total lines were characterized by lowest value of tassel blast, leaf firing, leaf area index with highest value of cob diameter and length, ear per plant, number of kernel row/ear, number of kernel/ear, number of kernel row, shelling percentage, silk receptivity and grain yield in heat stress condition. Since this cluster of lines had superior trait value for heat stressed condition, these lines may be of interest to researchers.

Table 2: Distance among the different cluster centroid of maize under heat stress at NMRP, Rampur,Chitwan (2016).

\begin{tabular}{|c|c|c|c|c|}
\hline & Cluster1 & Cluster2 & Cluster3 & Cluster4 \\
\hline Cluster 1 & 0 & 614.977 & 398.599 & 750.397 \\
\hline Cluster 2 & & 0 & 247.245 & 158.825 \\
\hline Cluster 3 & & & 0 & 399.583 \\
\hline Cluster4 & & & & 0 \\
\hline
\end{tabular}

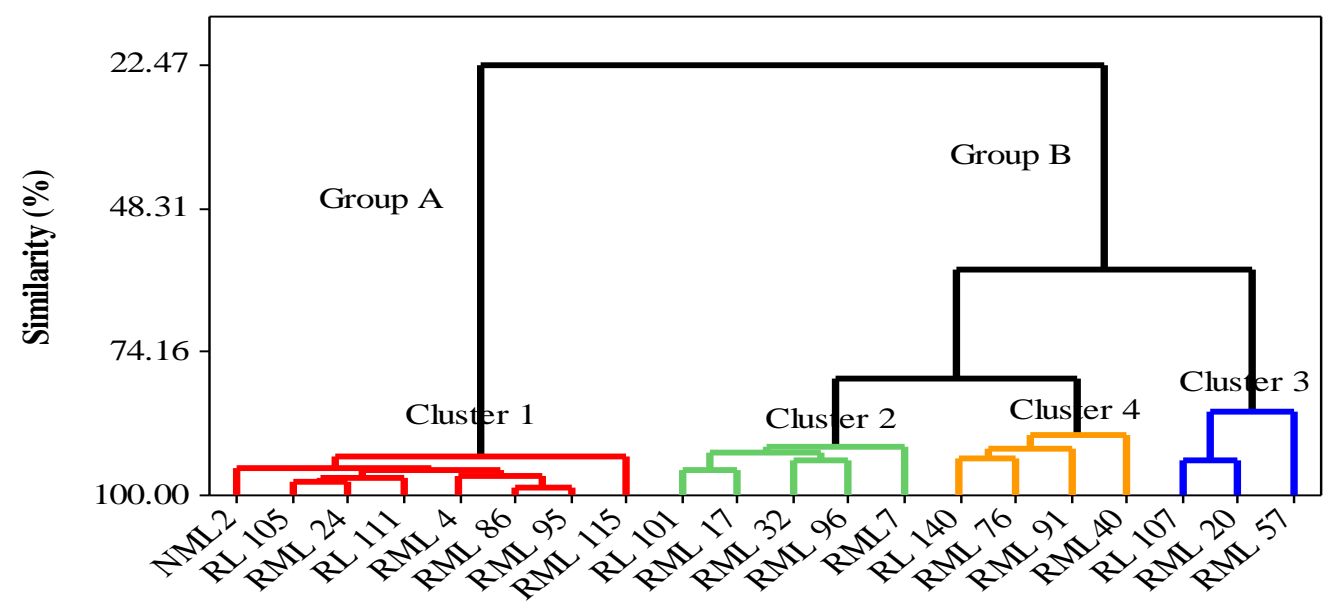

Maize inbred lines

Figure2: Cluster analysis of 20 maize inbred lines evaluated for agro-morphological traits under heat stress at NMRP, Rampur, Chitwan (2016). 
Journal of Maize Research and Development (2017) 3 (1): 86-97

ISSN: 2467-9291 (Print), 2467-9305 (Online)

DOI: http://dx.doi.org/10.3126/jmrd.v3i1.18925

Table 3: Mean of Clustering of 20 Maize inbred lines under heat stress condition at NMRP, Rampur, Chitwan (2016).

\begin{tabular}{llllll}
\hline Variable & Cluster 1 & Cluster 2 & Cluster 3 & Cluster 4 & Centroid \\
\hline No. of inbred lines & & & & & \\
Anthesis silking interval & 5.06 & 2.8 & 3 & 4 & 20 \\
Leaf area index & 2.83 & 2.55 & 2.53 & 3.37 & 3.8 \\
SPAD Chlorophyll & 33.209 & 41.31 & 42.93 & 40.56 & 38.16 \\
Leaf firing & 26.35 & 14.88 & 11.6 & 5.75 & 17.13 \\
Tassel blast & 47.51 & 28.64 & 27.33 & 26.825 & 35.63 \\
Plant height & 131.25 & 130.78 & 125.133 & 129.45 & 129.85 \\
Ear height & 71.06 & 65.74 & 59.833 & 63.8 & 66.59 \\
Physiological maturity & 107.563 & 105 & 104.16 & 107.75 & 106.47 \\
Leaf sensense & 58.75 & 72 & 68.33 & 60 & 63.75 \\
Ear per plant & 1.18 & 1.066 & 1.323 & 1.143 & 1.16 \\
Cob diameter & 0 & 2.69 & 2.77 & 2.93 & 1.677 \\
Cob length & 0 & 11.46 & 8.43 & 11.64 & 6.37 \\
Number of kernel row per ear & 0 & 11.04 & 10.76 & 11.35 & 6.64 \\
Number of kernel row & 0 & 12.26 & 13.26 & 13.825 & 7.82 \\
Number of kernel per ear & 0 & 56.46 & 49.73 & 102.37 & 42 \\
Silk receptivity & 0 & 27.1 & 21.76 & 35.95 & 17.23 \\
Shelling percentage & 0 & 51.17 & 25.44 & 50.89 & 26.78 \\
Thousand kernel weight (g) & 0 & 285.32 & 260.467 & 271.825 & 164.76 \\
Grain yield (kg ha ${ }^{-1}$ ) & 0 & 537.68 & 293.4 & 688.05 & 316.04 \\
\hline
\end{tabular}

\section{Principal Component Analysis}

The PCA showed close resemblance with clustering and partitioned the total variance into 4 PCs having eigen value $>1$ explanining $85.9 \%$ of total vaiation with eigen value between 10.935 to 1.293, among 20 lines of maize under heat stress,However, the remaning componnent contributed only $14.4 \%$ towards total diversity for this set of maize lines.The first three pricipal component (PC1) which explained $79.2 \%$ was associated mainly by anthesis silking interval $(0.257)$,tassel blast $(0.229)$, leaf firing $(0.216)$ and leaf area index $(0.120)$ with negative loading with grain yield, cob diameter (-0.295), cob length (-0.275), number of kernel/ear (-0.275),number of kernel/row (-0.297), number of kernel/ear (-0.298), shelling percentage(-0.276), silk receptivity $(-0.295)$ and thousand kernel weight(-0.297) due to some heat susceptible lines in this cluster. Second principal (PC2) was responsible for about $13.4 \%$ was mainly related to positively for leaf firing (0.239), physiological maturity $(0.258)$. $\operatorname{SPAD}(0.145)$ and anthesis silking interval (0.106)with negatively for leaf area index $(-0.273)$,tassel blast $(-0.176)$,ear height $(-0.538)$,ear per plant(-0.258), leaf senescence(-0.149) and grain yield(-0.008).PC3 contributed 8.3\% with major positive contributor are leaf senescence $(0.585)$ fallowed by leaf firing $(0.218)$ whereas negatively associated with anthesis-silking interval (-0.104) leaf area index(-0.283), plant height($0.147)$,ear height(-0.186), physiological maturity(-0.565) and grain yield(-0.135).PC4 accounted $6.8 \%$ of the total variation was mainly negative association with, leaf area index $(-0.489)$, leaf firing (-0.024), tassel blast (-0.139), leaf senescence(-0.397),SPAD(-0.201), shelling percentage($0.058)$ and thousand kernel weight(-0.009) and positive association with anthesis-silking interval (0.154), grain yield (0.024), ear per plant (0.708), silk receptivity (0.030), plant height $(0.708)$, 
Journal of Maize Research and Development (2017) 3 (1): 86-97

ISSN: 2467-9291 (Print), 2467-9305 (Online)

DOI: http://dx.doi.org/10.3126/jmrd.v3i1.18925

number of kernel row/ear (0.026), number of kernel/ear (0.087) and number of kernel/row (0.087).Thus positive relation with grain yield, anthesis silking interval, number of kernel row/ear, number of kernel/ear and number of kernel row, etc. and negative association with tassel blast, leaf firing, leaf senescence, ear height, thousand kernel weight, shelling percentage lead to this principal component had variability and selection within this is importance for heat stress condition as shown in Table 3.The present research revealed that these genotype formed in cluster four in heat stress condition were found most tolerant to heat stress. The finding PCA supported the result obtained by cluster analysis and PCA score plot was shown in figure 3 .

Table 3: The first four principal components of traits used for cluster analysis and PCA and the eigen analysis of the correlation matrix at NMRP, Rampur,Chitwan (2016).

\begin{tabular}{|c|c|c|c|c|}
\hline \multirow[b]{2}{*}{ Variable } & \multicolumn{4}{|c|}{ components } \\
\hline & $\mathrm{PC} 1$ & $\mathrm{PC} 2$ & $\mathrm{PC} 3$ & PC4 \\
\hline Eigenvalue & 10.935 & 2.545 & 1.569 & 1.293 \\
\hline Proportion & 0.578 & 0.133 & 0.083 & 0.068 \\
\hline Cumulative & 0.578 & 0.71 & 0.792 & 0.860 \\
\hline Anthesis silking interval & 0.257 & 0.106 & -0.104 & 0.154 \\
\hline Leaf area index & 0.120 & -0.273 & -0.283 & -0.489 \\
\hline SPAD Chlorophyll & -0.200 & 0.145 & -0.216 & -0.201 \\
\hline Leaf firing & 0.216 & 0.239 & 0.218 & -0.024 \\
\hline Tassel blast & 0.229 & -0.176 & 0.074 & -0.139 \\
\hline Plant height & 0.03 & -0.591 & -0.147 & 0.039 \\
\hline Ear height & 0.097 & -0.538 & -0.186 & -0.035 \\
\hline Physiological maturity & 0.103 & 0.258 & -0.565 & -0.009 \\
\hline Leaf senescence & -0.086 & -0.149 & 0.585 & -0.397 \\
\hline Ear per plant & 0.025 & -0.265 & 0.141 & 0.708 \\
\hline Cob diameter & -0.295 & -0.031 & 0.046 & -0.023 \\
\hline Cob length & -0.275 & -0.032 & 0.001 & -0.011 \\
\hline Number of kernel row per ear & -0.297 & -0.039 & 0.019 & 0.026 \\
\hline Number of kernel row & -0.298 & -0.003 & -0.000 & 0.048 \\
\hline Number of kernel per ear & -0.275 & -0.052 & -0.192 & 0.087 \\
\hline Silk receptivity & -0.295 & -0.02 & -0.093 & 0.030 \\
\hline Shelling percentage & -0.281 & -0.016 & -0.008 & -0.058 \\
\hline Thousand kernel weight & -0.297 & -0.015 & 0.070 & -0.009 \\
\hline Grain yield (kg/ha) & -0.286 & -0.008 & -0.135 & 0.022 \\
\hline
\end{tabular}




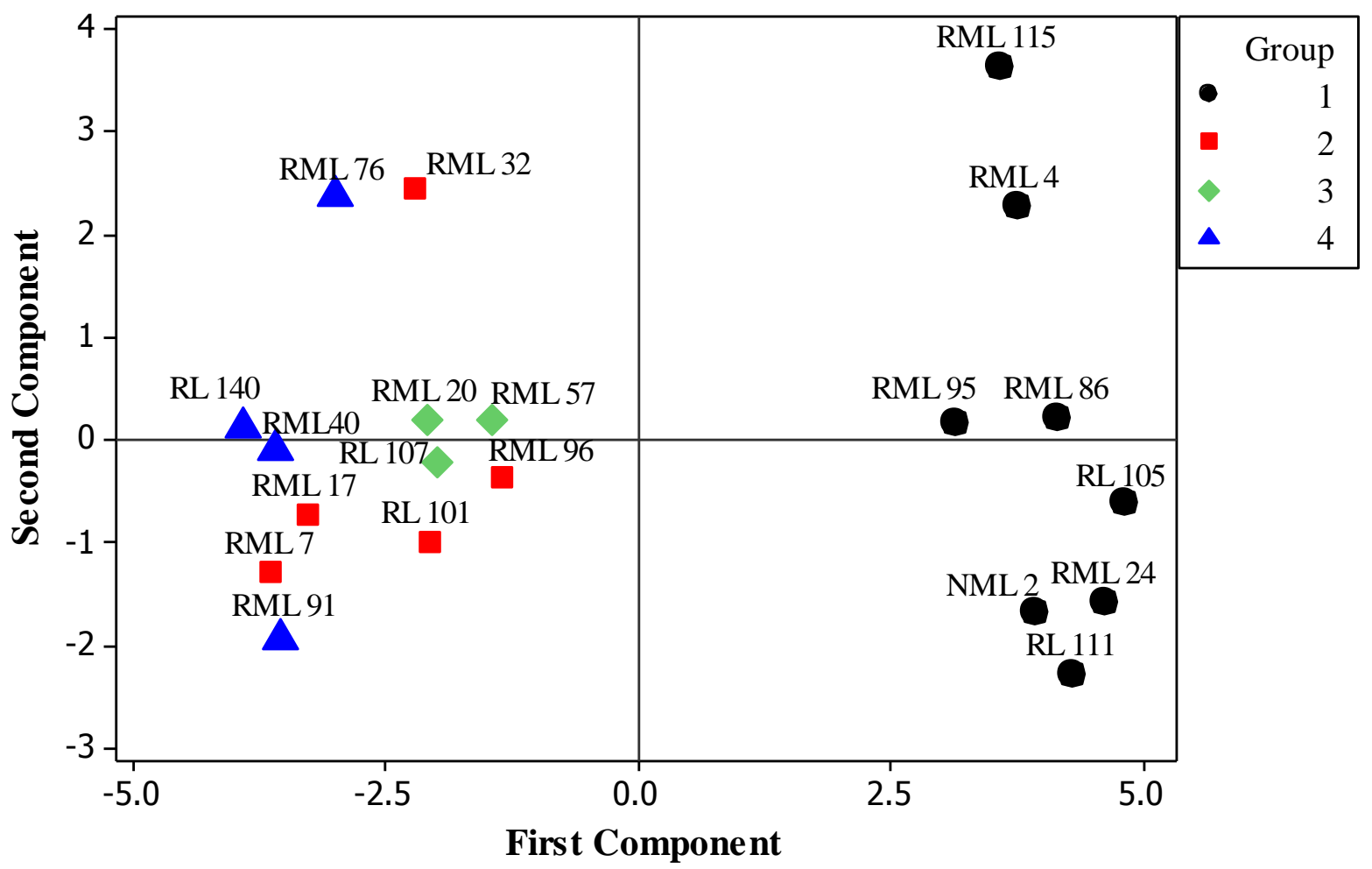

Fig 3: The score plot of first two components of maize inbred lines under heat stress at NMRP Rampur, Chitwan (2016).

\section{DISCUSSION}

In present study there is sustainable genetic diversity in grain yield and heat tolerance trait. Khodarahmpour et al. (2011) reported similar finding reduced grain yield up to $70 \%$ under heat stress condition in maize inbred lines. Grain yield reduction was associated with poor pollen viability under heat stress condition reported by Rowhani et al. (2011).Pre-anthesis stress in plants absorption of fertilized structure and reduced ear growth rate lead to reduction in kernel number leading to barrenness and ultimate affect crop yield reported by Cicchino et al., (2010b). There were four considerable genetic divergence groups due to genetic factor also subjected to environmental factor. Shrestha (2016) also reported that significant amount of genetic diversity for in maize inbred line for their different morphological traits. Krupakar et al. (2009) also have assessed the range of variability of 16 genotypes for 14 traits in maize. The presence of divergent cluster indicated their superior trait value for heat stressed condition; these inbred lines may be of interest to researcher for abiotic stress breeding. Souza and Sorrels (1991) also reported estimation of genetic diversity and relationships among germplasm accessions facilitates the selection of parents with diverse genetic background which is very essential for breeding program. Thus similar finding about presence of genetic diversity in maize yield and its component were also reported by Singh and Chaudharai (2003).In present study cluster 4 were most heat stress tolerance this finding similar by Ali et al. (2008) who reported that cluster analysis can be useful for finding high yielding genotypes. In this study of principal component 
Journal of Maize Research and Development (2017) 3 (1): 86-97

ISSN: 2467-9291 (Print), 2467-9305 (Online)

DOI: http://dx.doi.org/10.3126/jmrd.v3i1.18925

use to reduces of original variables into four principal component and information about each variable which support cluster analysis result. These findings were similar to the results founded by Syafii et al. (2015) and Kamara et al. (2003).In present finding multivariable analysis help to selection of inbred lines for heat stress tolerance breeding: similar to the results reported by Akte ret al., (2009).

\section{CONCLUSION}

The genetic diversity was observed in inbred lines differences for grain yield and anthesis silking interval, SPAD reading and leaf senescence, tassel blast and leaf firing percentage, plant and ear height, leaf area index, ear per plant, cob length and diameter, number kernel ear ${ }^{-1}$, number of kernel rowear ${ }^{-1}$, number kernel row, silk receptivity, shelling percentage, thousand kernel weight under heat stress condition. UPGMA revealed that inbred lines formed four distinct clusters. The resistant lines and susceptible lines formed different clusters. The member of cluster 4 was found to be tolerance to heat stress where as members of cluster 1 were found most susceptible to heat stress. From this study inbred lines RL-140, RML-76, RML-91 and RML-40 were found most tolerant to heat stress as shown by lower reduction in grain yield and heat tolerance trait tassel blast, leaf firing and shorter anthesis siliking interval. The PCA showed close resemblance with clustering. The presence of high level of diversity among the inbred line for heat stress tolerance grouped into divergent cluster indicated their superior trait value for heat stressed condition; these inbred lines may be of interest to researcher for abiotic stress breeding.

\section{ACKNOWLEDGEMENTS}

The authors would to thank to National Maize Research Program, Rampur, Chitwan, Nepal for the provision of reseach support.

\section{AUTHOR CONTRIBUTIONS}

S.K.G., B. R.O. and J. S. designed the experiment in research field research. M. K. performed experiments, analyzed data and wrote manuscript. S. K. G. and J. S. gave final approval of the manuscript version to be published.

\section{CONFLICTS OF INTEREST}

The authors declare that there is no conflict of interest.

\section{REFERENCES}

Akter, A., Hasan, M. J., Paul, A. K., Mutlib, M. M., \& Hossain, M. K. (2009).Selection of parent for improvement of restorer line in rice (Oryza Sativa L.). SAARC Journal of Agriculture, 7(2), 43-50.

Ali, F., Kanwal, N., Ahsan, M., Ali, Q., \& Niazi, N. K. (2015). Crop improvement through conventional and non-conventional breeding approaches for grain yield and quality traits in Zea mays. Life Science Journal, 12(4s).

Ali, Y., Atta, B. M., Akhter, J., Monneveux, P., \& Lateef, Z. (2008).Genetic variability, association and diversity studies in wheat (Triticum aestivum L.) germplasm. Pak. J. Bot, 40(5), 2087-2097. 


\section{Journal of Maize Research and Development (2017) 3 (1): 86-97 \\ ISSN: 2467-9291 (Print), 2467-9305 (Online) \\ DOI: http://dx.doi.org/10.3126/jmrd.v3i1.18925}

Asare, S., Tetteh, A. Y., Twumasi, P., Adade, K. B., \& Akromah, R. A. (2016).Genetic diversity in lowland, midaltitude and highland African maize landraces by morphological trait evaluation. African Journal of Plant Science, 10(11), 246-257.

Carangal, V.R., Ali, S.M., Koble, A.F., \& Rinke, E.H. (1971). Comparison of S1 with testcross evaluation for recurrent selection in maize. Crop Science, 11, 658-661.

Cicchino, M., Edreira, J. I., Uribelarrea, M., \& Otegui, M. E. (2010b). Heat stress in field-grown maize: Response of physiological determinants of grain yield. Crop science, 50(4), 14381448

Dhaka, B. L., Meena, B. S., \& Suwalka, R. L. (2010).Popularization of improved maize production technology through frontline demonstrations in south-eastern Rajasthan. Journal of Agricultural Sciences, 1(1), 39-42.

Kamara, A. Y., Kling, J. G., Menkir, A., \& Ibikunle, O. (2003). Agronomic performance of maize (Zea mays L.) breeding lines derived from a low nitrogen maize population. The Journal of agricultural science, 141(2), 221-230.DOI:10.1017/S0021859603003514.

Khan, H., Marwat, K. B., Khan, M. A., \& Hashim, S. (2014). Herbicidal control of parthenium weed in maize. Pak. J. Bot, 46(2), 497-504.

Khodarahmpour, Z., \& Choukan, R. (2011). Genetic variation of maize (Zea mays L.) inbred lines in heat stress condition. Seed and Plant Improvment Journal, 27(4), 539-554.

Marker, S., \&Krupakar, A. (2009).Genetic divergence in exotic maize germplasm (Zea mays L.). Journal of Agricultural and Biological Science, 4(4), 44-47.

MoAD (2015/16) Statistical Information on Nepalese Agriculture.Agri business promotion and statistical division, Agristatistic section, Singhdurbar, Kathmandu.

Niyogi, D., Kishtawal, C., Tripathi, S., \& Govindaraju, R. S. (2010). Observational evidence that agricultural intensification and land use change may be reducing the Indian summer monsoon rainfall. Water Resources Research, 46(3).

Rincon, F., Johnson, B., Crossa, J., \& Taba, S. (1996). Cluster analysis. An approach to sampling variability in maize [Zea mays L.] accessions. Maydica (Italy).

Rosegrant, M. W., \& Agcaoili, M. (2010). Global food demand, supply, and prices prospects.International food policy research Institute, Washington, DC, USA.

Rowhani, P., Lobell, D. B., Linderman, M., \& Ramankutty, N. (2011).Climate variability and crop production in Tanzania. Agricultural and Forest Meteorology, 151(4), 449-460.

Shrestha, J., Koirala, K., Katuwal, R., Dhami, N., Pokhrel, B., Ghimire, B., Prasai, H., Paudel, A., Pokhrel, K., \& KC, G. (2015). Performance evaluation of quality protein maize genotypes across various maize production agro ecologies of Nepal. Journal of Maize Research and Development, 1(1), 21-27. doi:http://dx.doi.org/10.3126/jmrd.v1i1.14241

Shrestha, J. (2016). Cluster Analysis of Maize Inbred Lines. Journal of Nepal Agricultural Research Council, 2, 33-36.

Singh, P. K., \&Chaudhari, L. B. (2001).Genetic divergence in maize (Zea mays L.). Journal of Research-Birsa Agricultural University, 13(2), 193-196

Smith, J. S. C., \& Smith, O. S. (1989).The description and assessment of distance between inbred lines of maize. 2: The utility of morphological-biochemical-and genetic descriptors and a scheme for the testing of distinctiveness between inbred lines [in USA]. Maydica (Italy).

Souza, E., \& Sorrells, M. E. (1991). Relationships among 70 North American oat germplasms: I. Cluster analysis using quantitative characters. Crop Science, 31(3), 599-605. 
Journal of Maize Research and Development (2017) 3 (1): 86-97

ISSN: 2467-9291 (Print), 2467-9305 (Online)

DOI: http://dx.doi.org/10.3126/jmrd.v3i1.18925

Syafii, M., Cartika, I., \& Ruswandi, D. (2015).Multivariate analysis of genetic diversity among some maize genotypes under maize-albizia cropping system in Indonesia. Asian Journal of Crop Science, 7(4), 244.

Van der Velde, M., Wriedt, G., \& Bouraoui, F. (2010).Estimating irrigation use and effects on maize yield during the 2003 heatwave in France. Agriculture, ecosystems \& environment, 135(1), 90-97. 